\title{
Embedding cyclic nitrone in mesoporous silica particles for EPR spin trapping of superoxide and other radicals
}

Received 00th January 20xx, Accepted 00th January 20xx DOI: $10.1039 / \times 0 \times x 00000 x$

Eric Besson, *a Stéphane Gastaldi, ${ }^{a}$ Emily Bloch, Jacek Zielonka, ${ }^{c, d}$ Monika Zielonka, ${ }^{\text {c,d }}$ Balaraman Kalyanaraman, ${ }^{\mathrm{c}, \mathrm{d}}$ Selma Aslan, ${ }^{a}$ Hakim Karoui, ${ }^{a}$ Antal Rockenbauer, ${ }^{\mathrm{e}, \mathrm{f}}$ Olivier Ouari ${ }^{\mathrm{a}}$ and Micael Hardy*a

\begin{abstract}
The generation of superoxide radical anion in biological systems is one of the major initiating events in the redox biology of NADPH oxidases and mitochondrial redox signalling. However, the pallette of chemical tools for superoxide detection is very limited, hampering progress in understanding the chemical biology of superoxide. Although EPR spin trapping is regarded as the most rigorous technique for superoxide detection, rapid reduction of the EPR-active superoxide spin adducts to EPRsilent hydroxylamines, or to hydroxyl radical adducts by bioreductants, significantly limits the applicability of this technique in biological systems. To overcome these limitations, in this work, we report the synthesis and characterization of a new mesoporous silica functionalized with a phosphorylated cyclic spin trap (DIPPMPO nitrone). The DIPPMPO-grafted silica is a versatile spin-trap agent enabling the identification of a wide range of carbon or oxygen-centered transient radicals in organic and in aqueous media. Moreover, superoxide was efficiently trapped under in vitro conditions in both cell-free and cellular systems. The generated superoxide adduct exhibited an exceptional half-life of $3.5 \mathrm{~h}$ and a resistance toward bioreductant agents such as glutathione for several hours.
\end{abstract}

\section{Introduction}

Electron paramagnetic resonance (EPR) spectroscopy is a powerful tool in biological studies, as it allows to detect and identify paramagnetic species in chemical, enzymatic and biological systems in a non-invasive manner. Moreover, EPR spectra provide rich information on the structure and electronic properties of the species detected, and are highly sensitive to both the surrounding and the mobility of the paramagnetic species. However, the direct EPR detection of free radicals is often prevented by their short lifetime in solution at room temperature, leading to a steady-state concentration below the detection limit, as well as by unsuitable relaxation properties such as those observed for alkoxy radicals. To overcome these limitations, an indirect method has been devised: the spin trapping (ST) technique, which enables detection and characterisation of short-lived radicals in solution at room

\footnotetext{
a. Aix Marseille Univ, CNRS, ICR, Marseille, France.

b. Aix Marseille Univ, CNRS, MADIREL, Marseille, France.

c. Department of Biophysics, Medical College of Wisconsin, Milwaukee, WI 53226, USA

d. Free Radical Research Center, Medical College of Wisconsin, Milwaukee, WI 53226, USA.

e. Institute of Materials and Environmental Chemistry, Research Centre for Natural Sciences, Hungarian Academy of Sciences, 1117 Budapest, Hungary.

f. Department of Physics, Budapest University of Technology and Economics, Budafoki ut 8, 1111 Budapest, Hungary.

Electronic Supplementary Information (ESI) available: Details of syntheses, NMR spectra of the prepared compounds, EPR spectra, and experimental procedures. See DOI: 10.1039/x0xx00000x
}

temperature, by converting them into long-lived spin adducts with characteristic EPR spectroscopic properties. ${ }^{1-3}$

The ST technique, with its origins in the 1960s, is based on the specific reaction of a free radical with a nitrone or nitroso spin trap to form a more persistent nitroxide spin adduct that is conveniently detected by EPR spectroscopy (Scheme 1).4-7 Typically, the EPR spectra of spin adducts exhibit very characteristic hyperfine splitting pattern, enabling the identification of the trapped short-lived radical species. Combining ST with EPR spectroscopy is one of the most reliable methods to unambiguously detect and characterize free radicals. It is noteworthy that ST has benefited in its development from the growing interest of life science researchers in the fine investigation of biological free radical processes, as illustrated by the superoxide radical anion.

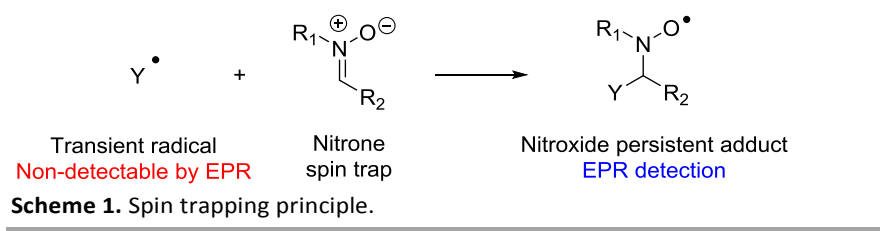

Since the discovery of superoxide dismutase enzymes (SOD) in the late 1960s and early 1970s, the knowledge on the formation of superoxide radical anion $\left(\mathrm{O}_{2}{ }^{--}\right)$in biological systems has advanced to an astonishing degree, motivated by the wide implications of $\mathrm{O}_{2}{ }^{\bullet-}$ in human physiology. $\mathrm{O}_{2}{ }^{\bullet-}$, a product of oneelectron reduction of molecular oxygen, has been implicated in the pathogenesis of multiple diseases as well as in physiological signalling processes. These range from cell signalling and cell- 
function-modifying roles to inflammation, ageing, and many major diseases such as diabetes, neurodegenerative pathologies (Alzheimer's and Parkinson diseases), several types of cancer, atherosclerosis, and ischemia/reperfusion injuries (e.g., stroke, organ transplantation). ${ }^{8} \mathrm{O}_{2}{ }^{\bullet-}$ is the primary species produced in the cascade of reactive oxygen and nitrogen species (RONS) generation.

The gathered knowledge on the role of $\mathrm{O}_{2}{ }^{--}$and downstream RONS served to establish the relevance of RONS and the redox status in cell function and dysfunction, and led to a better understanding of redox control of key biological processes. These developments have substantial significance in biology and medicine. ${ }^{9}$ However, in order to unambiguously establish the role of a specific molecule in a biological event, a reliable method for its detection and characterisation is required. ${ }^{10-13}$

Despite the advances in the understanding of the chemical biology of $\mathrm{O}_{2}{ }^{--}$and the tremendous effort devoted to the development of sensors for $\mathrm{O}_{2}{ }^{--}$, its reliable detection and quantification in vivo remains a challenge. This is mostly due to a very short lifetime of $\mathrm{O}_{2}{ }^{-}$, its low reactivity towards available probes, low steady-state concentration (at nM levels), and unfavourable spectroscopic properties. Very limited accumulation of $\mathrm{O}_{2}{ }^{--}$in biological systems is due mainly to the presence of specialised enzymatic defence mechanisms in cells against $\mathrm{O}_{2}{ }^{\circ-}$, including SODs (diffusion-limited reaction rate) and superoxide reductase enzymes (SORs). It should be noted that even in the absence of the other targets, $\mathrm{O}_{2}{ }^{--}$undergoes fast dismutation at physiological $\mathrm{pH}\left(\mathrm{k} \sim 10^{5} \mathrm{M}^{-1} \mathrm{~s}^{-1}\right)$, to produce hydrogen peroxide $\left(\mathrm{H}_{2} \mathrm{O}_{2}\right)$ and molecular oxygen $\left(\mathrm{O}_{2}\right)$. Thus, the direct detection of $\mathrm{O}_{2}{ }^{--}$is not conceivable, and methods for indirect detection have been tentatively developed over the last 40 years.

Several techniques have been applied for $\mathrm{O}_{2}{ }^{\bullet-}$ detection, e.g., fluorescence, luminescence, and EPR spin trapping. A number of probes (e.g., luminol, nitroblue tetrazolium, hydroethidine, spin traps, lucigenin) have been used for $\mathrm{O}_{2}{ }^{--}$detection, with the formation of easily detectable, relatively stable products that can accumulate with time, or produce a strong chemiluminescence signal. ${ }^{14-20}$ However, because of their chemical reactivity and because of the features of living systems, currently all these approaches have various drawbacks. Only a few of those probes yield products that are specific for $\mathrm{O}_{2}{ }^{\bullet-}$. These probes include lucigenin, hydroethidine (HE), and cyclic nitrone spin traps.

However, lucigenin undergoes redox-cycling, leading to selfgeneration of $\mathrm{O}_{2} \cdot-$, which significantly limits its use in biological systems and confounds data interpretation. ${ }^{21-23} \mathrm{HE}$ is one of the most promising probes to detect $\mathrm{O}_{2}{ }^{-}$. The reaction of $\mathrm{HE}$ with superoxide $\left(\mathrm{O}_{2}{ }^{-}-/ \mathrm{HO}_{2}{ }^{\circ}\right)$ is relatively fast at $\mathrm{pH} 7.4$ (apparent rate constant at $\mathrm{pH} 7.4$ was estimated as $\sim 10^{4} \mathrm{M}^{-1} \mathrm{~s}^{-1}$ ) and generates 2-OH-E $\mathrm{E}^{+}$as a specific $\mathrm{O}_{2}{ }^{--}$marker product. However, the chemical reactivity of $\mathrm{HE}$ towards other oxidants and the spectroscopic properties of $\mathrm{O}_{2}{ }^{\cdot-}$-independent oxidation products (e.g., ethidium cation and dimers) limits its use for in vitro and in vivo detection of $\mathrm{O}_{2}{ }^{\cdot-}$ by fluorescence imaging, and requires a separation step using chromatographic techniques. ${ }^{24}$
Although spin trapping of $\mathrm{O}_{2}{ }^{--}$using cyclic nitrones was found to be very useful and efficient for the detection and the identification of $\mathrm{O}_{2}{ }^{--}$in cell-free systems in vitro, the lifetime of the corresponding adducts and their fast reduction to EPR silent products limits their use in biological systems. ${ }^{25-27}$ In addition, the superoxide adduct to the most commonly used cyclic nitrone, DMPO, is not stable and undergoes spontaneous conversion in water to the hydroxyl radical adduct within minutes. This has been addressed by the development of newer spin traps, including DEPMPO, BMPO, and more recently DIPPMPO, which produce more stable superoxide adducts that do not convert into hydroxyl radical adducts in the absence of reductants. However, in the presence of biologically relevant reducing systems, like glutathione (GSH) and glutathione/glutathione peroxidase (GSH/GPx), such conversion will still occur. This significantly limits the ability to unambiguously identify the superoxide adduct, and may lead to misidentification of the radical species trapped. Different strategies have been proposed to increase the lifetime of superoxide spin adduct, and macrocycles such as $\beta$ cyclodextrins have been shown to partially protect spin adducts from reduction by GSH and GSH/GPx systems (CD-DIPPMPO, Figure 1). ${ }^{28-31}$ However, only few particle-based strategies have been reported so far for EPR detection of free radicals, such as phenyl-tert-butylnitrone (PBN) as glycolipidic vesicles, ${ }^{32}$ and as 5,5-dimethyl-1-pyrroline $\mathrm{N}$-oxide (DMPO) grafted onto gold nanoparticles, ${ }^{33}$ or adsorbed into silica gel. ${ }^{34}$

Recently, we showed that nanostructured silicas functionalized with radical precursors led to dramatically increased lifetimes of the transient radicals, such as arylsulfany| ${ }^{35-37}$ or arylsulfinyl radicals. ${ }^{38}$ This increase in lifetime was observed regardless the location of the precursors either in the framework or on the pores of the silica. Moreover, these systems enabled the direct EPR observation of these species at room temperature or higher, which was not feasible without the silica matrix.
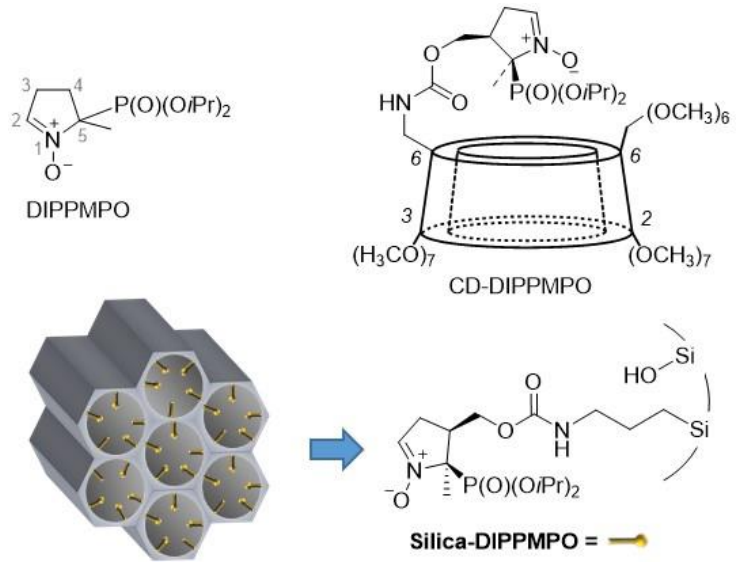

Figure 1. Chemical structures of the DIPPMPO nitrone, and a schematic representation of the cyclodextrin-conjugated (CD-DIPPMPO) and silica-bound DIPPMPO (Silica-DIPPMPO)

In this study, the ability to increase the lifetime of radical species by silica particles has been extended to spin adduct radicals, with the hypothesis that the confinement into the pores will limit the reaction with enzymes (GPX, cytochrome P450 for instance) and with polar reductants, and will cancel bimolecular decay of the spin adducts. A new mesoporous silica 
functionalized in the pores with a nitrone spin trap, DIPPMPO, has been designed (Silica-DIPPMPO, Figure 1). Its ST behaviour towards various carbon-centered radicals has been evaluated in organic and aqueous media. Finally, the ST efficiency with regards to oxygen centered radicals, including $\mathrm{O}_{2}{ }^{\circ}$, has been investigated as well as the resistance of the superoxide adduct against bioreductive agents. As a proof of principle we also demonstrated the ability of the Silica-DIPPMPO to trap $\mathrm{O}_{2}{ }^{-}$ produced by live cells in the in vitro system.

\section{Materials and methods}

\section{Materials}

All reagents were used as received without further purification. The reactions were monitored by TLC on silica gel Merck 60F254 and by ${ }^{31} \mathrm{P}$ nuclear magnetic resonance (NMR). ${ }^{31} \mathrm{P} \mathrm{NMR}$ and ${ }^{13} \mathrm{C}$ NMR spectra were recorded with a Bruker DPX 400 and Bruker Avance III WB 400 spectrometers. Chemical shifts ( $\delta$ ) are reported in ppm and coupling constant $J$ values in Hertz. Xanthine oxidase $(X O)$ and SOD were from Sigma-Aldrich. The amino-propyl-SBA $15\left(\mathrm{SBA}_{15}-\mathrm{NH}_{2}\right)^{39}$ and NHS-DIPPMPO 40 were prepared according to procedures in the literature (see $\mathrm{SI}$ ).

\section{Synthesis of Silica-DIPPMPO}

To a mixture of NHS-DIPPMPO $(0.072 \mathrm{~g}, 0.6 \mathrm{mmol})$ and $\mathrm{SBA}_{15-}$ $\mathrm{NH}_{2}(0.200 \mathrm{~g}, 0.25 \mathrm{mmol})$ in acetonitrile $(10 \mathrm{~mL})$ at room temperature under argon, triethylamine $(53 \mathrm{~mL}, 0.52 \mathrm{mmol}$ ) was added. The reaction mixture was stirred for $12 \mathrm{~h}$. Then, the reaction mixture was filtered and washed successively with $\mathrm{CH}_{2} \mathrm{Cl}_{2}$, EtOH, acetone, and $\mathrm{Et}_{2} \mathrm{O}(2 \times 50 \mathrm{~mL}$ each). A white powder was obtained corresponding to the Silica-DIPPMPO (0.220 g). ${ }^{31}$ P MAS ssNMR $\delta 18.0 ;{ }^{13} \mathrm{C}$ MAS ssNMR $\delta 157.1,145.0$, 140.4, 75.4, 73.7, 72.0, 65.4, 59.2, 57.2, 46.1, 43.4, 29.9, 23.2, 19.8, 17.4, 14.2, 9.0. TGA data in SI.

\section{Experimental procedures for EPR analyses}

EPR spectra were recorded at room temperature at $9.5 \mathrm{GHz}$ (Xband) employing $100 \mathrm{kHz}$ field modulation. Unless otherwise indicated, the spectrometer settings were as follows: microwave power, $10 \mathrm{~mW}$ (a); modulation amplitude, $1 \mathrm{G}$; smooth point, 1; gain $90 \mathrm{~dB}$; sweep time, $40.96 \mathrm{~s}$; conversion time, $40 \mathrm{~ms}$. Computer simulations were performed using the ROKI-EPR program..$^{41}$ For experiments with an organic solvent, Silica-DIPPMPO and a solution of reactants were introduced in a $4 \mathrm{~mm}$ quartz EPR tube that was deoxygenated by freeze/thaw cycles before EPR analysis.

Trapping of tert-butylperoxyl radical: $t-\mathrm{BuOOH} / \mathrm{hv}$ System. The tert-butylperoxyl (t-BuOO*) radical adduct was generated by photolysis of $\mathrm{t}-\mathrm{BuOOH}(1.5 \mathrm{M})$ in the presence of SilicaDIPPMPO (30 mg/mL) in deoxygenated toluene.

Trapping of the tert-butoxyl radical: $t-B u O O-t-B u / h v$ System. The tert-butoxyl (t-BuO*) radical adduct was generated by photolysis of ditert-butylperoxide $(0.5 \mathrm{M})$ in the presence of Silica-DIPPMPO $(30 \mathrm{mg} / \mathrm{mL})$ in deoxygenated toluene.

Trapping of the methyl radical. The methyl $\left({ }^{\circ} \mathrm{CH}_{3}\right)$ radical adduct was generated by photolysis of $\mathrm{Mel}(1 \mathrm{M})$ in the presence of bis(tributyltin) $(0.03 \mathrm{M})$ and Silica-DIPPMPO $(30 \mathrm{mg} / \mathrm{mL})$ in deoxygenated toluene.
For experiments in aqueous media, samples were prepared in an Eppendorf tube and mixed rapidly to start the incubation and form a homogenous suspension of the silica particles. The suspension was then transferred into a glass Pasteur pipette, which was sealed with Critoseal (from Leica) before EPR analysis.

Trapping of carbon-centered radicals. The carbon centered radicals were generated by addition of $\mathrm{FeSO}_{4}(2 \mathrm{mM})$ to a suspension of Silica-DIPPMPO (30 mg/mL), dtpa (1 mM), $\mathrm{H}_{2} \mathrm{O}_{2}$ (2 $\mathrm{mM}$ ) and $20 \%$ (by vol.) of $\mathrm{MeOH}, \mathrm{EtOH}$, or $\mathrm{HCOONa}$ in phosphate buffer (0.1 M, pH 7.3).

Trapping of superoxide radical anion: hypoxanthine-xanthine oxidase system. Xanthine oxidase $(0.04$ or $0.4 \mathrm{U} / \mathrm{mL}$ ) was added to an $\mathrm{O}_{2}$-saturated solution of Silica-DIPPMPO $(30 \mathrm{mg} / \mathrm{mL})$, dtpa $(0.1 \mathrm{mM})$, and hypoxanthine $(0.4 \mathrm{mM})$ in phosphate buffer $(0.1$ $\mathrm{M}, \mathrm{pH}$ 7.3).

Trapping of superoxide radical anion: $\mathrm{KO}_{2} / 18$-crown-6 ether system. The EPR signal was observed upon rapid addition of a DMSO solution of $\mathrm{KO}_{2}(10 \mathrm{mM})$ and 18 -crown-6 ether $(10 \mathrm{mM})$ to a phosphate buffer solution $(0.1 \mathrm{M}, 100 \mu \mathrm{L})$ containing SilicaDIPPMPO (30 mg/mL).

Trapping of superoxide radical anion: cellular system. Differentiated human promyelocytic leukemia HL60 cells ( $d$ HL60 cells) were used as a cellular model for in vitro superoxide spin trapping. Cells were differentiated into neutrophil-like cells by treatment with all-trans-retinoic acid (ATRA), as described previously. ${ }^{42,43}$ Briefly, HL60 cells were incubated with ATRA ( $1 \mu \mathrm{M})$ for $4-5$ days, cells counted, and medium replaced by HBSS-containing HEPES ( $25 \mathrm{mM}, \mathrm{pH} 7.4)$ and dtpa $(0.1 \mathrm{mM})$ immediately before EPR measurements. Generation of $\mathrm{O}_{2}{ }^{--}$was stimulated by activation of NADPH oxidase-2 (Nox2) with phorbol myristate acetate (PMA, $1 \mu \mathrm{M}$ ). The final suspension contained $5 \times 10^{6}$ cells $/ \mathrm{mL}$ and $35 \mathrm{mg} / \mathrm{mL}$ Silica-DIPPMPO.

Kinetics of decay of the superoxide spin adduct in the presence and absence of reducing agents. The hypoxanthine/xanthine oxidase $(\mathrm{HX} / \mathrm{XO})$ system was used to generate $\mathrm{O}_{2}{ }^{--}$in phosphate buffer $(0.1 \mathrm{M}, \mathrm{pH} 7.3,100 \mu \mathrm{L})$ at room temperature and the superoxide adduct was monitored in the presence of the considered system [DIPPMPO $(20 \mathrm{mM})$ alone, DIPPMPO (20 $\mathrm{mM}$ ) with SBA-15 silica $(30 \mathrm{mg} / \mathrm{mL})$, and Silica-DIPPMPO (30 $\mathrm{mg} / \mathrm{mL}$ )]. Once the steady-state levels of the superoxide adduct were reached, superoxide adduct formation was stopped by the addition of a large excess of SOD $(600 \mathrm{U} / \mathrm{mL})$ with or without reductants ( $1 \mathrm{mM} \mathrm{GSH}$ or $0.5 \mathrm{mM}$ ascorbate) and EPR spectra were recorded over time.

Xanthine oxidase activity. The xanthine oxidase activity was determined using xanthine as a substrate and by monitoring the uric acid formation by UV absorption at $296 \mathrm{~nm}$ as previously described. ${ }^{44}$

\section{Results and Discussion}

Functionalisation of mesoporous silica with a cyclic nitrone 
DIPPMPO cyclic nitrone (Figure 1) is one of the most efficient commercially available spin trap used for the detection of $\mathrm{O}_{2}{ }^{\circ-}$. To extend the lifetime of the radical adducts and limit the reduction of the adduct by bioreductants, we embedded DIPPMPO in the mesoporous silica particles. Because of the limited stability of DIPPMPO under acidic conditions, the functionalisation of the mesoporous silica was performed by grafting. We have previously reported that the NHS-DIPPMPO derivative is the precursor of choice for an easy functionalisation (Scheme 2). ${ }^{40}$ This phosphorylated nitrone enabled the cis-grafting of molecules of interest (biotin,

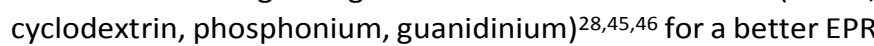
signature of the superoxide adduct, resulting in a better identification of the radicals trapped. Moreover, the NHS group is located in position 4 of the 5 -membered nitrone ring, leading to an enhancement of the persistency of the superoxide adduct. ${ }^{47}$

The Silica-DIPPMPO was prepared by grafting through the formation of a carbamate linker between NHS-DIPPMPO and an amino-functionalised SBA-15 silica $\left(\mathrm{SBA}_{15}-\mathrm{NH}_{2}\right)$ (Scheme 2). Briefly, the synthesis of the mesoporous silica functionalised on the surface of the pores is based on the direct synthesis methodology. ${ }^{48}$ It includes a hydrolytic copolymerization process between tetraethylortosilicate (TEOS) and an organotrialkoxysilane in acidic medium. Due to the acidic conditions, the amine function was derivatised with the tertbutyloxycarbonyl (Boc) protecting group to ensure its localization in the pores. ${ }^{39}$ This synthesis strategy of organicinorganic hybrid nano-structured materials, using the sol-gel process in the presence of structure-directing agents, enables engineering of functional nanostructured silicas in which the alkylamino groups are regularly distributed in the pores. DIPPMPO grafting was achieved by reacting NHS-DIPPMPO with the amino-functionalized SBA-15, as described in the experimental section and shown in Scheme 2.
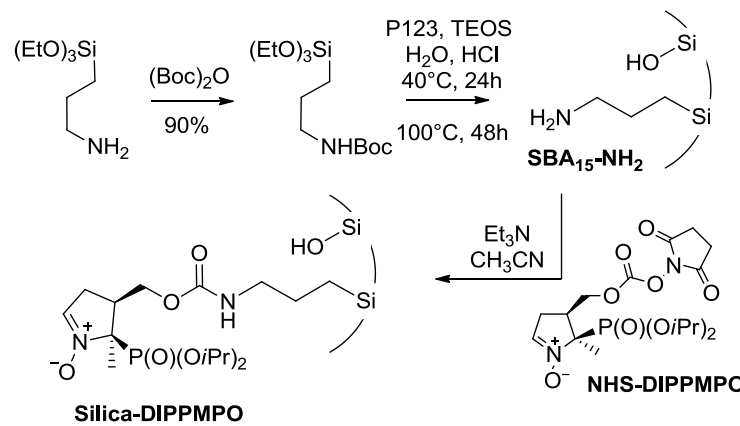

Scheme 2. Synthesis of Silica-DIPPMPO.

${ }^{13} \mathrm{C}$ and ${ }^{31} \mathrm{P}$ solid-state NMR analyses were performed to confirm the DIPPMPO grafting and to monitor the formation of a covalent bond between the spin trap and the silica (carbamate signal at $157.1 \mathrm{ppm}$, see SI). The resulting Silica-DIPPMPO was obtained with a grafting ratio of $0.23 \mathrm{mmol} / \mathrm{g}$ determined both by thermogravimetric analysis (TGA) and quantitative ${ }^{31} \mathrm{P}$ solidstate NMR spectroscopy. This corresponds to a density of 0.2 function $/ \mathrm{nm}^{2}$ in the functionalized silica with a pore diameter of $9.1 \mathrm{~nm}$ (see SI).

\section{Spin trapping using Silica-DIPPMPO}

The ST efficiency of the Silica-DIPPMPO was investigated by EPR. The ST experiments provided information on the availability of the nitrones to react with free radicals including $\mathrm{O}_{2}{ }^{--}$and to test the resistance of the Silica-DIPPMPO-OOH adduct to bioreductive agents.

\section{Spin trapping in aqueous media}

Spin trapping of carbon-centered radicals. The first experiments were dedicated to the trapping of various carbon-centered radicals. The Fenton-generating system in the presence of methanol, ethanol, or formic acid was used to generate the corresponding radicals via hydrogen abstraction. The EPR spectra exhibited a main isotropic pattern (Figure 2). The spectra were simulated using the ROCKI program ${ }^{41}$ (Figure 2) and the derived EPR parameters are shown in Table 1. The EPR parameters obtained are nearly identical to those observed for the same radicals using CD-DIPPMPO as a spin trap, supporting the assignment of the spin adducts. ${ }^{46}$

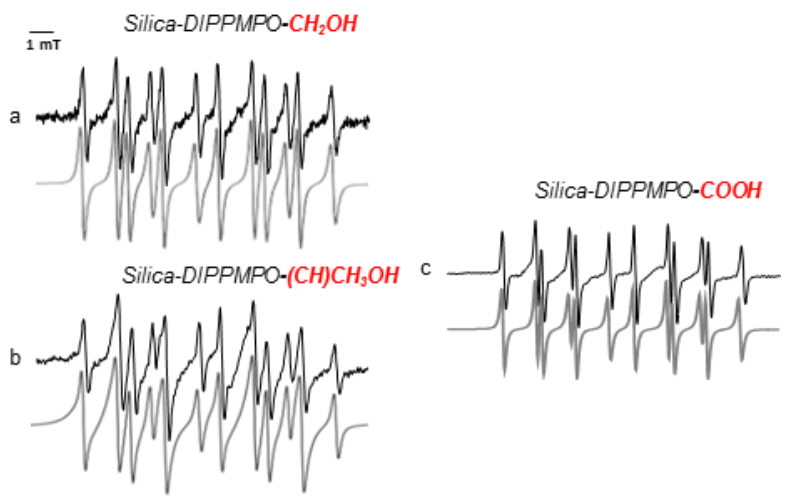

Figure 2. Spin trapping of carbon-centered radicals using Silica-DIPPMPO. (a) EPR spectrum obtained after 10 min incubation of a mixture containing Fe ${ }^{2+}(2 \mathrm{mM}), \mathrm{H}_{2} \mathrm{O}_{2}(2$ $\mathrm{mM})$, diethylenetriaminepentaacetic acid (DTPA) (1 mM), $\mathrm{MeOH}(20 \%)$, and SilicaDIPPMPO (3 mg) in phosphate buffer (0.1 M, pH 7.3). (b) As in (a) but in the presence of $\mathrm{EtOH}(20 \%)$. (c) As in (a) but in the presence of HCOONa (20\%). The gray lines represent the computer simulation of the spectrum with parameters given in Table 1 . Spectrometer settings: microwave power $10 \mathrm{~mW}$; modulation amplitude, $1 \mathrm{G}$; time constant, 1.28 ms; gain, 90; sweep time, 30 s; conversion time, 29.3 ms.

Spin trapping of superoxide radical anion in cell-free systems. To test the ability of Silica-DIPPMPO to trap $\mathrm{O}_{2}{ }^{--}$and form the superoxide adduct (Silica-DIPPMPO-OOH), 3 different $\mathrm{O}_{2}{ }^{--}$ generating systems were used, (i) $\mathrm{HX} / \mathrm{XO}$, (ii) $\mathrm{KO}_{2}$ in $\mathrm{DMSO}$ containing 18-crown-6 ether, and (iii) photolysis of $\mathrm{H}_{2} \mathrm{O}_{2}$, and in all 3 cases the same EPR spectrum was observed (Figure 3 ). All spectra appeared as doublets of distorted quartets resulting from hyperfine couplings with ${ }^{31} \mathrm{P},{ }^{14} \mathrm{~N}$, and ${ }^{1} \mathrm{H} \beta$ atoms.

In the presence of SOD, no EPR signal was detected (Figure $3 b$ ). The rate constant of disproportionation of $\mathrm{O}_{2}{ }^{--}$by SOD $(\mathrm{k}=2 \times$ $\left.10^{9} \mathrm{M}^{-1} \mathrm{~S}^{-1}\right), 49$ close to the diffusion rate, results in rapid scavenging of $\mathrm{O}_{2}{ }^{--}$, preventing its trapping by the nitrone. The efficiency of SOD in the quenching of $\mathrm{O}_{2}{ }^{--}$indicates that $\mathrm{O}_{2}{ }^{--}$is generated outside the silica and then diffuses into the pores, where it is trapped by silica-bound DIPPMPO. As mentioned above, the EPR signal of Silica-DIPPMPO-OOH generated with 
$\mathrm{HX} / \mathrm{XO}$ system was identical to the one obtained from the potassium superoxide $\left(\mathrm{KO}_{2}, 10 \mathrm{mM}\right)$ in the presence of 18 crown-6 ether and DMSO (10\%) or using UV-photolysis of $\mathrm{H}_{2} \mathrm{O}_{2}$ $(10 \%)$ in a phosphate buffered solution (Figure $3 c$ and e). This confirms that the trapped species is $\mathrm{O}_{2}{ }^{\bullet-}$.
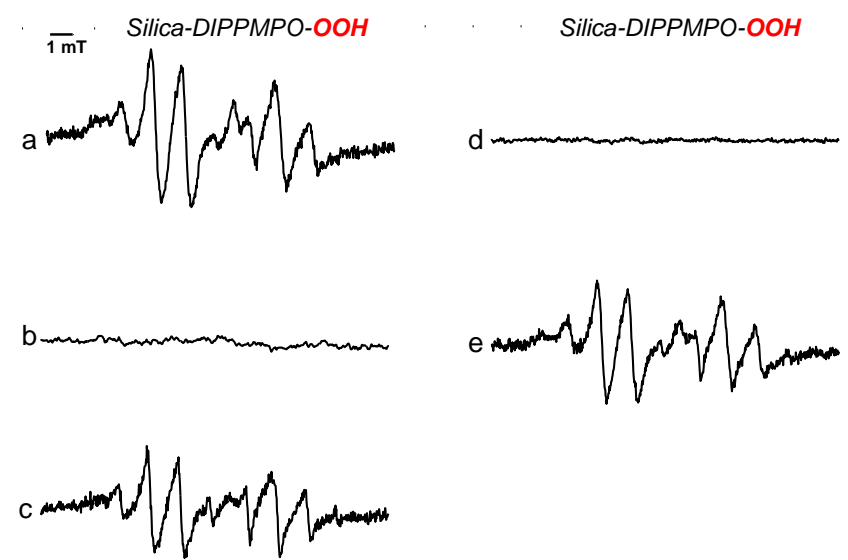

Figure 3. Spin trapping of superoxide radical anion using Silica-DIPPMPO. (a) EPR spectrum recorded after $10 \mathrm{~min}$ incubation of a mixture containing $\mathrm{HX}(0.4 \mathrm{mM}), \mathrm{XO}$, $(0.04 \mathrm{U} / \mathrm{mL})$, dtpa $(1 \mathrm{mM})$, and Silica-DIPPMPO $(30 \mathrm{mg} / \mathrm{mL})$ in oxygen-saturated phosphate buffer (0.1 M, pH 7.3). (b) As in (a) but in the presence of SOD $(600 \mathrm{U} / \mathrm{mL})$. (c) EPR spectrum obtained after rapid mixing of Silica-DIPPMPO $(30 \mathrm{mg} / \mathrm{mL})$ with $\mathrm{KO}_{2}(10$ $\mathrm{mM}$ ) and 18-crown-6 ether (10 mM) in phosphate buffer (0.1 M, pH 7.3). (d) As in (c) in the absence of $\mathrm{KO}_{2}$. (e) EPR spectrum obtained by UV-photolysis of a mixture containing $\mathrm{H}_{2} \mathrm{O}_{2}(10 \%)$ and Silica-DIPPMPO $(30 \mathrm{mg} / \mathrm{mL})$ in phosphate buffer $(0.1 \mathrm{M}, \mathrm{pH} 7.3)$ Spectrometer settings: microwave power $10 \mathrm{~mW}$; modulation amplitude, $1 \mathrm{G}$; time constant, $1.28 \mathrm{~ms}$; gain, 90; sweep time, $30 \mathrm{~s}$; conversion time, $29.3 \mathrm{~ms} ; 3$ scans.

The EPR spectra exhibited a reduced-motion pattern (Figure 3). In order to increase the tumbling rate of the superoxide spin adduct, variable-temperature EPR experiments were performed in the temperature range from $10^{\circ} \mathrm{C}$ to $60^{\circ} \mathrm{C}$ (see SI). The signal pattern of Silica-DIPPMPO-OOH was similar at all temperatures tested. However, the signal-to-noise ratio was improved at $50^{\circ} \mathrm{C}$ (Figure $4 \mathrm{~b}$ ), which may be related to an improved efficiency of trapping of $\mathrm{O}_{2}{ }^{--}$radical combined with reduced interaction of the adduct- $\mathrm{OOH}$ with the silica at higher temperatures.

At this temperature, the calculation using EPR/ROKI program enabled extraction of key parameters. The best fit was obtained assuming both that (i) the trapping reaction yielded only the trans diastereoisomer (hydroperoxyl moiety on the opposite face to the phosphonate group), and (ii) a chemical exchange occurred between two exchanging conformational sites: $T_{1}\left(A_{P}\right.$ $\left.=5.32 \mathrm{mT}, \mathrm{A}_{\mathrm{N}}=1.36 \mathrm{mT}, \mathrm{A}_{\mathrm{H} \beta}=1.24 \mathrm{mT}\right)$ and $\mathrm{T}_{2}\left(\mathrm{~A}_{\mathrm{P}}=5.13 \mathrm{mT}, \mathrm{A}_{\mathrm{N}}\right.$ $=1.23 \mathrm{mT}, A_{H \beta}=1.13 \mathrm{mT}$ ). The calculated chemical exchange rate constant was $\mathrm{k}=2.94 \times 10^{8} \mathrm{~s}^{-1}$ with $44 \%$ of the trans diastereoisomer ( $\mathrm{HOO}-$ trans to $(\mathrm{EtO})_{2} \mathrm{P}(\mathrm{O})-$ ) and $56 \%$ of the cis diastereoisomer. It is worth noting that EPR pattern and parameters of Silica-DIPPMPO-OOH adduct are very close to those reported for $\beta$-cyclodextrin/DIPPMPO superoxide spin adduct (Figure 4).46,28 The reduced motions of the superoxide spin adducts can originate from interactions with silica surface that was less favourable for carbon-centered radical spin adducts.
Table 1. Parameters for hyperfine splitting constants (HFSC)

\begin{tabular}{|c|c|c|c|c|c|}
\hline Adducts & Generating Systems & $g$ Factor & $\begin{array}{c}a_{p} \\
(m T)\end{array}$ & $\begin{array}{c}\mathrm{a}_{\mathrm{N}} \\
(\mathrm{mT})\end{array}$ & $\begin{array}{l}\mathrm{a}_{\mathrm{H} \beta} \\
(\mathrm{mT})\end{array}$ \\
\hline $\begin{array}{c}\text { Silica-DIPPMPO- } \\
\mathrm{CH}_{2} \mathrm{OH}\end{array}$ & $\begin{array}{l}\mathrm{MeOH} / \text { Fenton } \\
\text { reagent/pH } 7.4\end{array}$ & 2.0054 & 5.73 & 1.44 & 1.93 \\
\hline $\begin{array}{c}\text { Sili-DIPPMPO- } \\
\mathrm{CH}\left(\mathrm{CH}_{3}\right) \mathrm{OH}\end{array}$ & $\begin{array}{c}\text { EtOH/Fenton } \\
\text { reagen/pH } 7.4\end{array}$ & 2.0054 & 5.72 & 1.44 & 1.97 \\
\hline Sili-DIPPMPO-COOH & $\begin{array}{c}\mathrm{HCOOH} / \text { Fenton } \\
\text { reagen/pH } 7.4\end{array}$ & 2.0054 & 5.56 & 1.42 & 1.66 \\
\hline $\begin{array}{c}\text { Silica-DIPPMPO-OOH } \\
\text { T1 (44\%) } \\
\text { T2 (56\%) }\end{array}$ & $\mathrm{HX} / \mathrm{XO}$ & 2.0054 & $\begin{array}{l}5.32 \\
5.13 \\
\end{array}$ & $\begin{array}{l}1.36 \\
1.23 \\
\end{array}$ & $\begin{array}{l}1.24 \\
1.13\end{array}$ \\
\hline $\begin{array}{c}\text { CD-DIPPMPO-OOH } \\
\text { T1 (54\%) } \\
\text { T2 (46\%) }\end{array}$ & $\mathrm{HX} / \mathrm{XO}$ & 2.0054 & $\begin{array}{l}5.30 \\
4.50 \\
\end{array}$ & $\begin{array}{l}1.28 \\
1.27 \\
\end{array}$ & $\begin{array}{l}1.21 \\
0.61 \\
\end{array}$ \\
\hline $\begin{array}{c}\text { CD-DEPMPO-OOH } \\
\text { T1 (70\%) } \\
\text { T2 (30\%) }\end{array}$ & $\mathrm{HX} / \mathrm{XO}$ & 2.0054 & $\begin{array}{l}5.32 \\
5.20\end{array}$ & $\begin{array}{l}1.28 \\
1.29\end{array}$ & $\begin{array}{l}1.23 \\
1.21\end{array}$ \\
\hline
\end{tabular}

Interestingly, the persistency of the spin adduct was nearly unaffected by the higher temperatures, contrary to the superoxide spin adducts of DIPPMPO in aqueous solutions, for which a sharp decrease of DIPPMPO-OOH lifetime at $37^{\circ} \mathrm{C}$ was observed. ${ }^{50}$ Indeed, the persistency of DIPPMPO-OOH declined significantly above $37^{\circ} \mathrm{C}$, whereas the temperature-induced decay of Silica-DIPPMPO-OOH began at $60^{\circ} \mathrm{C}$.

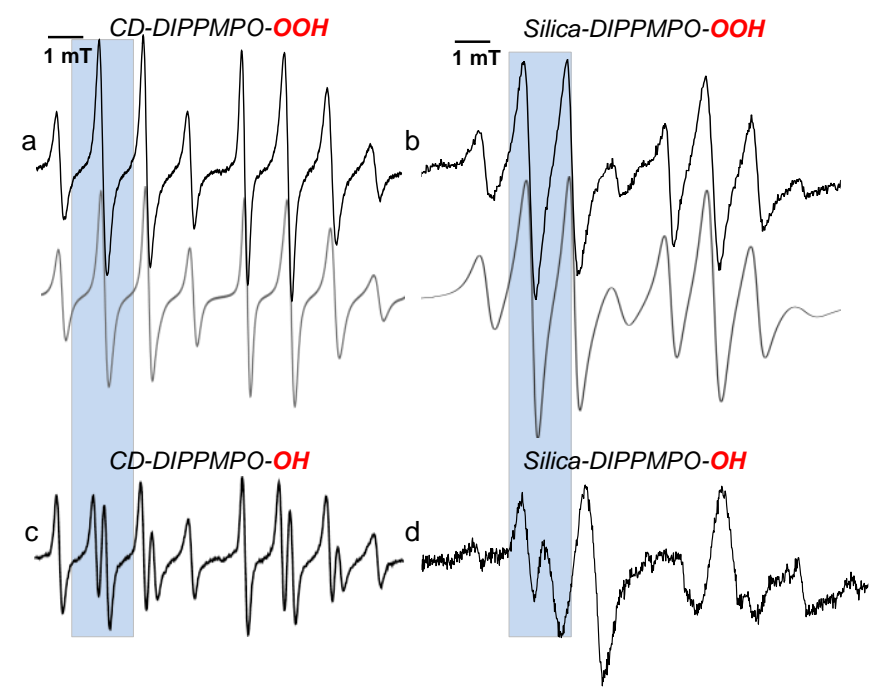

Figure 4. (a) EPR spectrum obtained after 14 min incubation of a mixture containing $\mathrm{HX}(0.4 \mathrm{mM}), \mathrm{XO}\left(0.04 \mathrm{U} \mathrm{mL}^{-1}\right)$, DTPA (1 mM) and CD-DIPPMPO (20 $\mathrm{mM}$ ) in oxygen-bubbled phosphate buffer (0.1 M, pH 7.3). (b) As in (a) but with Silica-DIPPMPO ( $3 \mathrm{mg}$ ) at $50^{\circ} \mathrm{C}$. (c) As in (a) but with GSH $1 \mathrm{mM}$. (d) As in (b) but with $\mathrm{EtB}(\mathrm{OH})_{2} 0.5 \mathrm{M}$ after $5 \mathrm{~h}$. Spectrometer settings: microwave power, $10 \mathrm{~mW}$ (a-d); modulation amplitude, 0.7G (a, c), $1 \mathrm{G} \mathrm{(b,} \mathrm{d);} \mathrm{time} \mathrm{constant,} 1.28 \mathrm{~ms}(\mathrm{a}-\mathrm{d})$; gain, $90(\mathrm{a}, \mathrm{c}), 75(\mathrm{~b}, \mathrm{~d})$; sweep time, $41.94 \mathrm{~s}(\mathrm{a}, \mathrm{c}), 30 \mathrm{~s}(\mathrm{~b}, \mathrm{~d})$; conversion time, $40.96 \mathrm{~ms}(\mathrm{a}, \mathrm{c}), 29.3 \mathrm{~ms}(\mathrm{~b}, \mathrm{~d})$; 1 scan (a, c), 3 scans (b), 5 scans (d).

To further support the assignment of the detected EPR spectrum to the superoxide adduct, and to demonstrate that the Silica-DIPPMPO-OOH and Silica-DIPPMPO-OH signals can be distinguished, the authentic hydroxyl radical adduct was generated by the direct reduction of the superoxide adduct into hydroxyl radical adduct using ethyl boronic acid (Figure $4 d$ )..$^{51}$ It 
is interesting to note that GPX/GSH system was not operative to converting Silica-DIPPMPO-OOH to Silica-DIPPMPO-OH, probably due to the confinement of the spin adducts in the pores. We propose that the ability of boronic acids and esters to reduce superoxide adducts to hydroxyl radical adducts can be used as a chemical tool for confirmation of the spectral assignment and characterisation of the hydroxyl radical adduct when other approaches (e.g., using Fenton's reagent) cannot be applied or produce a mixture of adducts.

All the experiments described above, involving different methods for generating $\mathrm{O}_{2}{ }^{--}$, the corresponding blank experiments, the reactivity of the spin adduct towards ethyl boronic acid, prevention of the adduct formation by SOD, the EPR line shape, and spectral parameters, support the hypothesis that the EPR signal shown in Figure $3 a$ is due to the trapping of superoxide radical anion.

Decay kinetics of Silica-DIPPMPO-OOH. The kinetics of decay of the superoxide radical adduct was determined by adding a large amount of SOD $\left(600 \mathrm{U} \mathrm{mL}^{-1}\right)$ to an incubation of $\mathrm{HX} / \mathrm{XO}$ with DIPPMPO, DIPPMPO in the presence of SBA-15 silica, or SilicaDIPPMPO after the adduct formation reached a steady-state concentration.

The decay curves were plotted from the full EPR signal intensity of the superoxide adducts, as determined from the double integrated EPR signal (Figure 5). The results indicate that the Silica-DIPPMPO-OOH adduct decays relatively slowly with time, and an apparent half-life of $\mathbf{2 1 0}$ min was estimated. To our knowledge, this is the highest persistency ever reported for any spin trap in water, applied for detecting superoxide radical anion. For comparison, the decay of DIPPMPO-OOH adduct in the presence of SBA-15 silica is plotted in Figure 5 with an apparent half lifetime of ca. $30 \mathrm{~min}$, consistent with previous reports. ${ }^{52}$
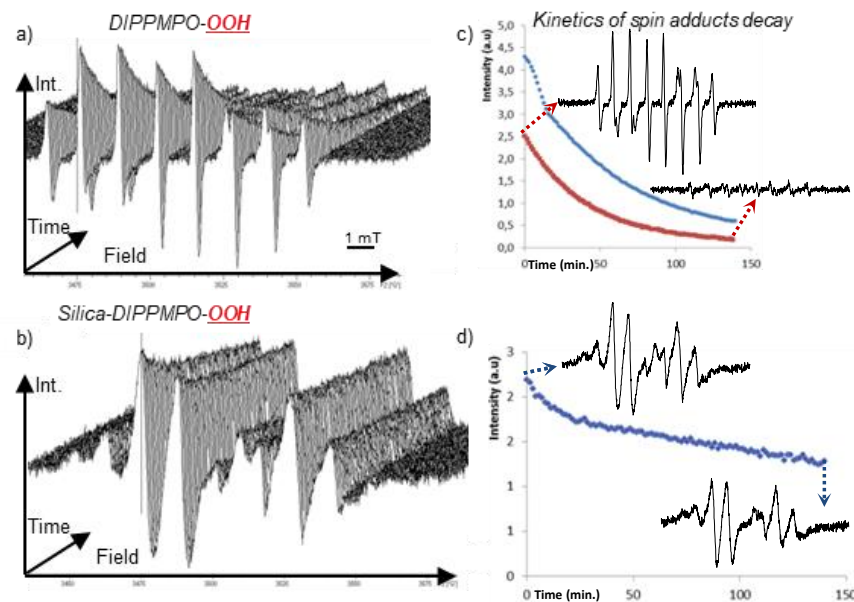

Figure 5. Kinetics of decay of (a) DIPPMPO-OOH and (b) Silica-DIPPMPO-OOH. Kinetics of decay of spin adducts generated by $\mathrm{HX}(0.4 \mathrm{mM}), \mathrm{XO}(0.4 \mathrm{U} / \mathrm{mL})$, dtpa $(1 \mathrm{mM})$ in an oxygenated phosphate buffer $(0.1 \mathrm{M}, \mathrm{pH} 7.3)$ was monitored after addition of SOD $(600 \mathrm{U} / \mathrm{mL})$. (c) Decay curves of the superoxide adduct for the DIPPMPO in the absence (red) or in the presence (blue) of silica (SBA-15). (d) Decay curve of the superoxide adduct for the Silica-DIPPMPO particles.

The increased persistence of the Silica-DIPPMPO-OOH compared to DIPPMPO-OOH adduct could be attributed to the confinement of the adduct- $\mathrm{OOH}$, preventing its disproportionation as hypothesised in previous works. ${ }^{53-55}$ Indeed, the reaction between two nitroxides bearing a hydrogen atom in the $\beta$-position leading to the corresponding hydroxylamine and the nitrone (both EPR silent) is unlikely due to the extremely low probability of the interaction between two spin adducts when they are covalently bonded to the silica.

Resistance of Silica-DIPPMPO-OOH. Further experiments were performed to evaluate the extent of the protective effect of the mesoporous silica against the reduction of the superoxide adduct by biologically relevant reductants. When the DIPPMPO superoxide spin adduct, DIPPMPO-OOH, is reduced with glutathione (GSH) (1 mM, 10 equivalents), its EPR signal is instantaneously replaced by the DIPPMPO-OH signal (Figure 6a, $c$, and e). Interestingly, when the same reduction was carried out with Silica-DIPPMPO-OOH, the superoxide adduct was the major species detected, even after more than $2 \mathrm{~h}$ of incubation (Figure 6).

This clearly demonstrates the ability of the silica particles to protect the superoxide adduct from the reduction by GSH. However, when the same experiments were performed in the presence of ascorbate $(1 \mathrm{mM})$, no protection by silica was observed (data not shown). This might be related to the relative affinity of the reductive agents to the silica surface, which would decrease the availability of GSH and, on the other hand, the impact of the refolding of the nitroxide moiety on the surface onto the efficiency of the reduction. We hypothesize that the protection of the superoxide adduct from reduction by ascorbate can be achieved by further fine-tuning the physical and chemical properties of the silica particles.

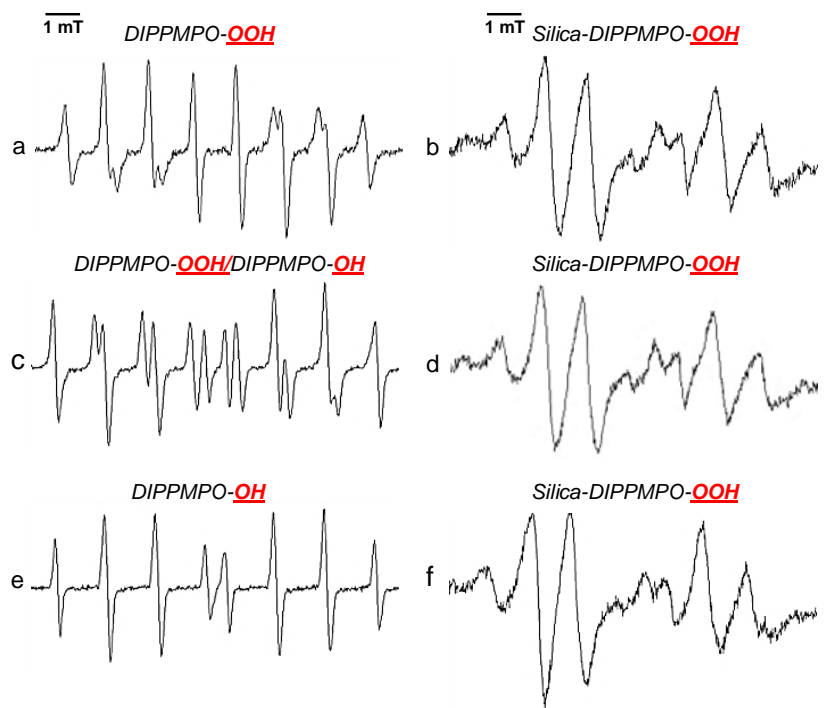

Figure 6. (a) EPR spectrum obtained after $10 \mathrm{~min}$ incubation of a mixture containing $\mathrm{HX}(0.4 \mathrm{mM}), \mathrm{XO}(0.04 \mathrm{U} / \mathrm{mL})$, dtpa $(1 \mathrm{mM})$, and DIPPMPO $(20 \mathrm{mM})$ in oxygenated phosphate buffer $(0.1 \mathrm{M}, \mathrm{pH} 7.3)$. (b) EPR spectrum obtained after 10 min incubation of a mixture containing $\mathrm{HX}(0.4 \mathrm{mM}), \mathrm{XO}(0.04 \mathrm{U} / \mathrm{mL})$, dtpa $(1 \mathrm{mM})$, and Silica-DIPPMPO ( $30 \mathrm{mg} / \mathrm{mL}$ ) in oxygenated phosphate buffer $(0.1 \mathrm{M}, \mathrm{pH} 7.3$ ). (c) As in (a) but in the presence of SOD $(600 \mathrm{U} / \mathrm{mL})$ and GSH (1 mM) after $1 \mathrm{~min}$. (d) As in (b) but in the presence of SOD $\left(600 \mathrm{U} / \mathrm{mL}^{-}\right)$and $\mathrm{GSH}(1 \mathrm{mM})$ after $1 \mathrm{~min}$. (e) As in (c) but after $150 \mathrm{~min}$. (f) As in (d) but after $150 \mathrm{~min}$.

We have previously shown that linking DIPPMPO to cyclodextrin increases superoxide adduct lifetime and lowers the detection limit. ${ }^{28}$ Embedding nitrone spin trap inside silica particles 
further increases the stability/lifetime of the superoxide adduct (Figure 5). However, due to silica particle size $(2-3 \mu \mathrm{m})$, it is forming heterogeneous suspension in aqueous solution, not optimal for absolute quantification of superoxide. We expect that further studies, using smaller size particles (e.g. nanoparticles $<200 \mathrm{~nm}$ ), will result in more homogenous mixtures, providing both high stability of the adduct and resistance to bioreductants with a good efficiency in superoxide trapping.

\section{Spin trapping of cell-derived superoxide radical anion.}

To test if the new spin trap can be used to detect $\mathrm{O}_{2}{ }^{--}$in a real biological system, we incubated the Silica-DIPPMPO spin trap with HL60 cells differentiated into neutrophil-like cells. Nonstimulated differentiated HL60 ( $d \mathrm{HL} 60)$ cells, when incubated with Silica-DIPPMPO, did not produce any detectable EPR signal (Figure 7, top trace). However, when the same incubation was performed in the presence of PMA, the EPR spectrum characteristic for the superoxide spin adduct was detected (Figure 7, middle trace). PMA treatment results in activation of NADPH oxidase-2, which catalyses the transfer of electrons from NADPH to molecular oxygen, with the generation of $\mathrm{O}_{2}{ }^{-}$ in the extracellular milieu. To further confirm the identity of the trapped species, we performed an analogous incubation in the presence of SOD (Figure 7, bottom trace). The lack of detectable signal confirms that the EPR signal detected is due to trapping of cell-derived $\mathrm{O}_{2}{ }^{\cdot-}$ by Silica-DIPPMPO.

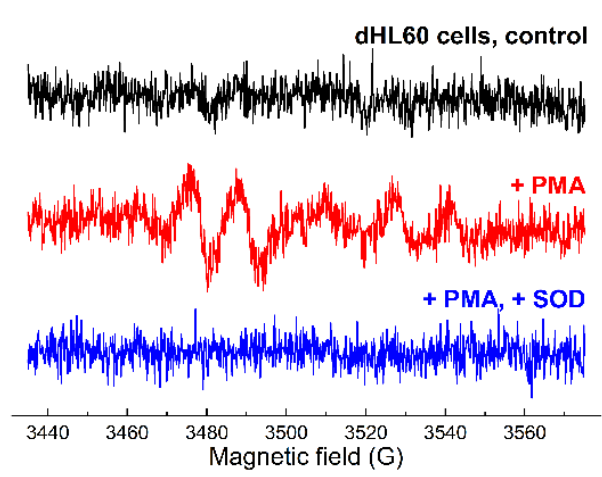

Figure 7. EPR spectra registered (1 scan) during spin trapping of cell-derived superoxide with Silica-DIPPMPO. dHL60 cells $(5 \times 106$ cells $/ \mathrm{ml})$ were incubated for $1 \mathrm{~h}$ with SilicaDIPPMPO ( $35 \mathrm{mg} / \mathrm{ml})$ in HBSS medium containing HEPES $(25 \mathrm{mM}, \mathrm{pH} 7.4)$ and dtpa (0.1 $\mathrm{mM}$ ). (Upper trace) no PMA was added; (middle trace) $1 \mu \mathrm{M}$ PMA was added; (lower trace) both PMA $(1 \mu \mathrm{M})$ and SOD $(0.2 \mathrm{mg} / \mathrm{ml})$ were added.

\section{Spin trapping in organic media}

To ascertain that the grafted nitrone was able to trap various free radicals, different types of radicals such as carboncentered, alkoxyl, and alkylperoxyl radicals were generated in toluene. We were able to trap and detect the spin adducts of $t$ $\mathrm{BuOO}^{\circ}, t$-BuO', and methyl radicals in toluene using SilicaDIPPMPO (Figure 8). In all these experiments, which were performed in an apolar organic solvent, EPR spectra exhibiting partially anisotropic features were recorded. We attribute this to the interaction of the spin adducts with the silica surface. ${ }^{36,56}$ This phenomenon has previously been reported in the study of the dynamics of the TEMPO radical anchored on the pore surface of mesoporous silica in various solvents. The solvation of the nitroxide moiety depends on the solvent characteristics. In apolar media, nitroxide radical moiety is refolded on the hydrophilic silica surface, decreasing the mobility of the spin label and resulting in the appearance of an anisotropic spectrum. ${ }^{57,58}$

Tert-butylperoxyl radical was produced in deoxygenated toluene by photolysis of $t-\mathrm{BuOOH}$ in the presence of SilicaDIPPMPO (Figure 8a). The EPR spectrum exhibited a slow motion pattern possibly due to the localization on the silica surface. Because of the large number of parameters, we were not able to reliably assign the hyperfine splitting constants. ${ }^{41}$ However, it must be noted that the EPR signal pattern of SilicaDIPPMPO-OOt-Bu and the one of Silica-DIPPMPO-OOH are similar, which is consistent with the results observed in the case of peroxyl adducts to other cyclic nitrones. ${ }^{59,60}$

It is interesting to note that for the photolysis of $t-\mathrm{BuOOH}$ in the presence of DIPPMPO and SBA-15 silica, the same EPR signal was detected as the one observed without silica, indicating that the presence of silica does not interfere with the trapping or detection of the peroxyl radical. ${ }^{61}$

UV-photolysis of $t$-BuOOt-Bu in the presence of Silica-DIPPMPO in deoxygenated toluene led to the detection of an EPR spectrum with a different line shape. The observed EPR signal exhibited a complex pattern probably due to the superimposition of different spin adducts originating from the trapping of carbon-centered radicals and possibly tert-butoxyl $(t$-BuO॰) radical (Figure $8 \mathrm{~b})$. No EPR signal was observed when Silica-DIPPMPO was irradiated in toluene solution without additives (Figure 8c).

Finally, an EPR spectrum of a methyl adduct was registered when Mel was irradiated in the presence of bis(tributyltin) and Silica-DIPPMPO in deoxygenated toluene (Figure 8d).
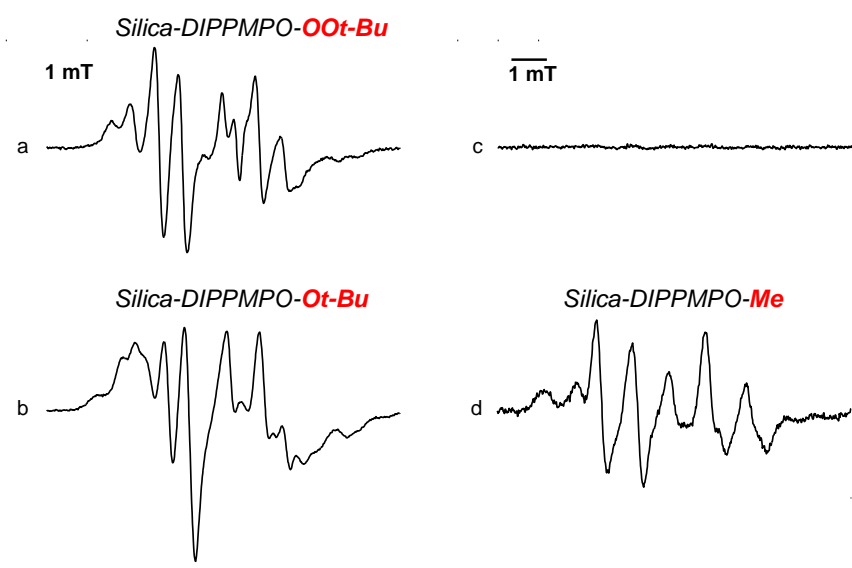

Figure 8. Spin trapping in organic media using Silica-DIPPMPO. (a) Signal obtained by UV-photolysis of a deoxygenated solution of $t$-BuOOH $(1.5 \mathrm{M})$ and SilicaDIPPMPO $(30 \mathrm{mg} / \mathrm{mL})$ in deoxygenated toluene. (b) As in (a) but in the presence of $t$-BuOOt-Bu (0.5 M). (c) As in (a) but in the absence of $t$-BuOOH. (d) As in (a) but in the presence of $\mathrm{Mel}(1 \mathrm{M})$ and bis(tributyltin) $(0.03 \mathrm{M})$. Spectrometer settings: microwave power, $10 \mathrm{~mW}$; modulation amplitude, $1 \mathrm{G}$; time constant, $1.28 \mathrm{~ms}$; gain, 90; sweep time, $30 \mathrm{~s}$; conversion time, $29.3 \mathrm{~ms}, 3$ scans.

This EPR study conducted in organic solvent evidenced the ability of silica-grafted DIPPMPO to trap radicals in a lipophilic 
environment, producing persistent adducts of oxygen- and carbon-centered radicals.

\section{Conclusions}

In conclusion, we have designed, synthesised, and characterised a novel spin trap, Silica-DIPPMPO, by covalent linking of DIPPMPO cyclic nitrone inside pores of mesoporous silica particles. EPR spectroscopic analyses in combination with computer-based simulations allowed us to characterise the spin adducts of various oxygen- and carbon-centered radicals, formed both in aqueous and apolar solvents. Silica-DIPPMPO exhibited high performance in the detection of superoxide radical anion, the primary reactive oxygen species produced in biological systems. The persistency of the EPR-active superoxide adduct to Silica-DIPPMPO is higher than for any spin trap reported to date. In addition, the Silica-DIPPMPO-OOH spin adduct is resistant to reduction by GSH, one of the major sources of low efficiency of EPR spin-trapping-based detection of superoxide in biological systems. The high persistency of the superoxide adduct and resistance to the reduction by GSH may allow the use of silica particle-conjugated spin traps in biochemical and biological systems. As a proof of principle, we show the feasibility to detect cell-derived superoxide using the newly synthesized Silica-DIPPMPO spin trap. Further structure optimization will be needed to minimize the penetration of the silica pores by other reducing species, such as ascorbate, with the goal of application of the particle-based spin traps to the in vivo systems.

\section{Acknowledgements}

The authors acknowledge the Agence Nationale de la Recherche for funding (ANR-16-CE07-0023-01 and ANR-12-JS07-005) and the support of the Hungarian National Research, Development and Innovation Office (NKFTH) Grant (K119442).

\section{Conflicts of interest}

There are no conflicts to declare.

\section{Notes and references}

1 E. G. Janzen and D. L. Haire, Adv. Free Rad. Chem., 1990, 1 253-295.

2 M. J. Turner and G. M. Rosen, J. Med. Chem., 1986, 29, 24392444.

3 M. J. Davies, B. C. Gilbert, C. Hazlewood and N. P. Polack, J. Chem. Soc., Perkin Trans 2, 1995, 13-21.

4 E. G. Janzen and B. J. Blackburn, J. Am. Chem. Soc., 1968, 90, 5909-5910.

5 C. Langercrantz and S. Forschult, Nature, 1968, 218, 12471248.

6 K. Ranguelova and R. P.Mason, Magn. Reson. Chem., 2011, 49, 152-158.

7 M. J. Davies, Methods. 2016, 109, 21-30.

8 B. Halliwell and J. M. C. Gutteridge, Free radicals in biology and medicine. 5th Edition, Oxford University Press, New York, 2015.
9 C. C. Winterbourn, Nat. Chem. Biol., 2008, 4, 278-286.

10 J. Zielonka, M. Zielonka, A. Sikora, J. Adamus, J. Joseph, M. Hardy, O. Ouari, B. P. Dranka and B. Kalyanaraman., J. Biol. Chem., 2012, 287, 2984-2995.

11 P. Wardman, Free Radic. Biol. Med., 2007, 43, 995-1022.

12 M. Hardy, J. Zielonka, H. Karoui, A. Sikora, R. Michalski, R. Podsiadły, M. Lopez, J. Vasquez-Vivar, B. Kalyanaraman and O. Ouari, Antioxid. Redox Signal., 2018, 28, 1416-1432.

13 J. Zielonka and B. Kalyanaraman, Free Radic. Biol. Med., 2018, 128, 3-22.

14 G. Bartosz, Clin. Chim. Acta, 2006, 368, 53-76.

15 S. Dikalov, K. K. Griendling and D. G. Harrison, Hypertension, 2007, 49, 717-727.

16 B. Halliwell and M. Whiteman, Br. J. Pharmacol., 2004, 142, 231-255.

17 M. M. Tarpey and I. Fridovich, Cir. Res., 2001, 89, 224-236.

18 M. M. Tarpey, D. A. Winkand and M. B. Grisham, Am. J. Physiol. Regul. Integr. Comp. Physiol., 2004, 286, R431-R444.

19 C. Frejaville, H. Karoui, B. Tuccio, F. Le Moigne, M. Culcasi, S. Pietri, R. Lauricella and P. Tordo. J. Med. Chem., 1995, 38, 258-265.

20 B. Kalyanaraman, M. Hardy, R. Podsiadly, G. Cheng and J. Zielonka, Arch. Biochem. Biophys., 2017, 617, 38-47.

21 I. Spasojevic, S. I. Liochev and I. Fridovich, Arch. Biochem. Biophys., 2000, 373, 447-450.

22 J. Vásquez-Vivar, N. Hogg, K. A. Jr Pritchard, P. Martasek and B. Kalyanaraman, Febs Lett., 1997, 403, 127-130.

23 P. Wardman, M. J. Burkitt, K. B. Patel, A. Lawrence, C. M. Jones, S. A. Everett and B. Vojnovic, J. Fluoresc., 2002, 12, 6568.

24 K. Dębowska, D. Dębski, M. Hardy, M. Jakubowska, B. Kalyanaraman, A. Marcinek, R. Michalski, B. Michałowski, O. Ouari, A. Sikora, R. Smulik and J. Zielonka, Pharmacol. Rep., 2015, 67, 756-764.

25 N. Beziere, M. Hardy, F. Poulhes, H. Karoui, P. Tordo, O. Ouari, Y. M. Frapart, A. Rockenbauer, J. L. Boucher, D. Mansuy and F. Peyrot, Free Radic. Biol. Med., 2014, 67, 150-158.

26 R. P. Mason, P. M. Hanna, M. J. Burkitt and M. B. Kadiiska, Environ. Health Perspect., 1994, 102 (Suppl. 10), 33-36.

27 C. L. Hawkins and M. J. Davies, Biochim. Biophys. Acta, 2014, 1840, 708-721.

28 M. Hardy, D. Bardelang, H. Karoui, A. Rockenbauer, J.-P. Finet, L. Jicsinszky, R. Rosas, O. Ouari and P. Tordo, Chem. Eur. J., 2009, 42, 11114-11118.

29 Y. Sueishi, A. Miyata, D. Yoshioka, M. Kamibayashi and Y. Kotake, J. Incl. Phenom. Macro., 2010, 66, 357-364.

$30 \mathrm{H}$. Karoui, A. Rockenbauer, S. Pietri and P. Tordo, Chem. Commun., 2002, 3030-3031.

31 Y. B. Han, B. Tuccio, R. Lauricella, A. Rockenbauer, J. L. Zweier and F. A. Villamena, J. Org. Chem., 2008, 73, 7108-7117.

32 O. Ouari, A. Polidori, B. Pucci, P. Tordo and F. Chalier, J. Org. Chem., 1999, 64, 3554-3556.

33 L. Du, S. Huang, Q. Zhuang, H. Jia, A. Rockenbauer, Y. Liu, K. Jian Liu and Y. Liu, Nanoscale, 2014, 6, 1646-1652.

34 C. J. Rhodes, I. D. Reid and U. Zimmermann, Chem. Commun., 2002, 1092-1093

35 F. Vibert, S. R. A. Marque, E. Bloch, S. Queyroy, M. P. Bertrand, S. Gastaldi and E. Besson, Chem. Sci., 2014, 5, 4716-4723.

36 F. Vibert, S. R. A. Marque, E. Bloch, S. Queyroy, M. P. Bertrand S. Gastaldi and E. Besson, J. Phys. Chem. C., 2015, 119, 54345439.

37 F. Vibert, E. Bloch, M. P. Bertrand, S. Queyroy, S. Gastaldi and E. Besson, New J. Chem., 2017, 41, 6678-6684.

38 F. Vibert, E. Bloch, M. P. Bertrand, S. Gastaldi and E. Besson, J. Phys. Chem. C., 2018, 122, 681-686.

39 A. Mehdi, C. Reye, S. Brandes, R. Guilard and R. J. P. Corriu, New J. Chem., 2005, 29, 965-968. 
40 M. Hardy, F. Poulhes, E. Rizzato, A. Rockenbauer, K. Banaszak, H. Karoui, M. Lopez, J. Zielonka, J. Vasquez-Vivar, S. Sethumadhavan, B. Kalyanaraman, P. Tordo and O. Ouari, Chem. Res. Toxicol., 2014, 27, 1155-1165.

41 A. Rockenbauer and L. Korecz, Appl. Magn. Reson., 1996, 10, 29-43.

42 J. Zielonka, G. Cheng, M. Zielonka, T. Ganesh, A. Sun, J. Joseph, R. Michalski, W. J. O'Brien, J. D. Lambeth and B. Kalyanaraman, J. Biol. Chem., 2014, 289, 16176-16189.

43 J. Zielonka, M. Zielonka, L. Verplank, G. Cheng, M. Hardy, O. Ouari, M. M. Ayhan, R. Podsiadły, A. Sikora, J. D. Lambeth, B. Kalyanaraman, J. Biol. Chem., 2016, 291, 7029-7044.

44 I. Wede, Z. Z. Altindag, B. Widner, H. Wachter and D. Fuchs, Free Radic. Res., 1998, 29, 331-338.

45 M. Hardy, F. Chalier, O. Ouari, J.-P. Finet, A. Rockenbauer, B. Kalyanaraman and P. Tordo, Chem. Comm., 2007, 1083-1085.

46 F. Poulhès, E. Rizzato, P. Bernasconi, R. Rosas, S. Viel, L. Jicsinszky, A. Rockenbauer, D. Bardelang, D. Siri, A. GaudelSiri, H. Karoui, M. Hardy and O. Ouari, Org. Biomol. Chem., 2017, 15, 6358-6366.

47 F. Chalier, M. Hardy, O. Ouari, A. Rockenbauer and P. Tordo, J. Org. Chem., 2007, 72, 7886-7892.

48 A. Mehdi, C. Reye and R. Corriu, Chem. Soc. Rev., 2011, 40, 563-574.

49 H. J. Forman and I. Fridovich, Arch. Biochem. Biophys., 1976, 168, 396-400.

50 M. Hardy, A. Rockenbauer, J. Vasquez-Vivar, C. Felix, M. Lopez, S. Srinivasan, N. Avadhani, P. Tordo and B. Kalyanaraman, Chem. Res. Toxicol., 2007, 20, 1053-1060.

51 A. Sikora, J. Zielonka, M. Lopez, A. Dybala-Defratyka, J. Joseph, A. Marcinek and B. Kalyanaraman, Chem. Res. Toxicol., 2011 24, 687-697.

52 O. Ouari, M. Hardy, H. Karoui and P. Tordo, Electron Paramag. Reson., 2011, 22, 1-40.

53 K. U. Ingold, K. Adamic, D. F. Bowman and T. Gillan, J. Am. Chem. Soc., 1971, 93, 902-908.

54 D. F. Bowman, J. L. Brokenshire, T. Gillan and K. U. Ingold, J. Am. Chem. Soc., 1971, 93, 6551-6555.

55 D. F. Bowman, T. Gillan and K. U. Ingold, J. Am. Chem. Soc., 1971, 93, 6555-6561.

56 François Vibert Thesis, Marseille 2013.

57 M. Tudose, T. Constantinescu, A. T. Balaban and P. Ionita, Appl. Surf. Sci., 2008, 254, 1904-1908.

58 M. F. Ottaviani, L. Mollo and B. Fubini, J. Colloid Interface Sci., 1997, 191, 154-165.

59 H. Karoui, F. Chalier, J.-P. Finet and P. Tordo, Org. Biomol. Chem., 2011, 9, 2473-2480.

60 H. Karoui, C. Nsanzumuhire, F. Le Moigne, M. Hardy, D. Siri, E. Derat, A. Rockenbauer, O. Ouari and. P. Tordo, Chem. Eur. J. 2014, 20, 4064-4071.

61 M. Hardy, O. Ouari, L. Charles, J.-P. Finet, G. lacazio, V. Monnier, A. Rockenbauer and P. Tordo, J. Org. Chem., 2005 70, 10426-10433. 